\title{
Potential benefits of using hydrogen sulfide, vitamin E and necrostatin- 1 to counteract acetaminophen-induced hepatotoxicity in rats
}

\author{
Saleh $\mathrm{NEH}^{1}$, Saad $\mathrm{AH}^{1}$, Elbassuoni EA ${ }^{1}$, El-Tahawy NF${ }^{2}$, Abdel-Hakeem EA ${ }^{1}$ \\ Medical Physiology Department, Faculty of Medicine, Minia University, Minia, Egypt. \\ shady@mu.edu.eg
}

\begin{abstract}
BACKGROUND: The use of acetaminophen (APAP) is increasing recently, especially with COVID-19 outbreaks. APAP is safe at therapeutic levels, however, an overdose can cause severe liver injury. This study aims to explore possible mechanisms involved in APAP-induced hepatotoxicity and compare different hepatoprotective agents, namely vitamin $\mathrm{E}$, hydrogen sulfide $\left(\mathrm{H}_{2} \mathrm{~S}\right)$ and necrostatin-1 (NEC-1).

METHODS: Adult male albino rats were divided into groups: Control group, APAP-induced hepatotoxicity group, Vitamin E-treated group, $\mathrm{H}_{2} \mathrm{~S}$-treated group and NEC-1-treated group. Serum levels for aspartate aminotransferase (AST), alanine aminotransferase (ALT), interleukin-33 (IL-33), tumor necrosis factor alpha (TNF- $\alpha$ ), reduced glutathione (GSH) and lipid profile were measured. Histopathological examinations of liver tissue with H\&E stain and immunohistochemistry for activated caspase-3 were also done.

RESULTS: APAP-treated group showed elevated liver transaminases, hyperlipidemia, and deficient liver anti-oxidative response together with disturbed hepatic architecture and increased immune-expression of activated caspase-3 in hepatic tissue. Pretreatment with vitamin E, $\mathrm{H}_{2} \mathrm{~S}$ or NEC-1 reversed the affected parameters. Vitamin $\mathrm{E}$ and $\mathrm{H}_{2} \mathrm{~S}$ showed greater improvement when compared to NEC-1.

CONCLUSION: Vitamin $\mathrm{E}, \mathrm{H}_{2}^{2} \mathrm{~S}$ and NEC-1 showed protective effects against APAP-induced hepatotoxicity, thus they may be used as an adjuvant therapy when APAP is indicated for long periods as is the case in COVID-19 patients (Tab. 2, Fig. 2, Ref. 45). Text in PDF www.elis.sk

KEY WORDS: acetaminophen, hepatotoxicity, apoptosis, necrostatin-1, vitamin $E, \mathrm{H}_{2} \mathrm{~S}$.
\end{abstract}

\section{Introduction}

With recent COVID-19 outbreaks and current pandemic status, there is a high demand and overuse of acetaminophen (APAP) as part of the symptomatic management of its associated febrile manifestations $(1,2)$. Hence, there is a strong urge to study the hazardous effects of APAP on liver parenchyma with subsequent hepatotoxicity secondary to its overuse.

APAP has been used in medical practice as an analgesic and antipyretic drug with concern and close attention paid to its main side effects on liver tissue (1). However, the unexpected and uncontrolled worldwide pandemic placed the medical practitioners and scientists in a critical situation requiring the decision whether to treat COVID-19 patients with therapy targeting the virus or employ symptomatic treatment of its clinical manifestations. One of the most obvious manifestations is pyrexia and generalized body aches which required a safe and strong antipyretic and analgesic,

${ }^{1}$ Department of Medical Physiology, Faculty of Medicine, Minia University, Minia, Egypt, and ${ }^{2}$ Department of Histology and Cell Biology, Faculty of Medicine, Minia University, Minia, Egypt

Address for correspondence: E.A. Abdel-Hakeem, Medical Physiology Department, Faculty of Medicine, Minia University, 61111 Minia, Egypt. Phone: +2.01117563163 and accordingly, APAP has returned to the top of the list of drugs to be investigated in terms of safety and possible side effects.

APAP is a safe drug at therapeutic levels. However, its overdose can cause severe liver injury in animals and humans $(3,4)$. The mechanisms by which APAP induces hepatotoxicity are complex and despite substantial progress in understanding the involved mechanisms during the last decades, many details are still unknown $(5,6)$.

Choosing an animal model of hepatotoxicity was a prerequisite to start the study. APAP-induced hepatotoxicity in rats was chosen because it induces hepatotoxicity with metabolic features that are the same as in humans (7).

The current study is an attempt to investigate the different pathophysiological mechanisms involved in APAP-induced hepatotoxicity including inflammatory response, oxidative stress and different cell death pathways. In addition, we will assess the role of three different hepatoprotective agents; necrostatin-1, vitamin E, and hydrogen sulfide $\left(\mathrm{H}_{2} \mathrm{~S}\right)$ in guarding against APAP-induced hepatotoxicity.

\section{Materials and methods}

\section{Animals}

Fifty adult male albino rats of local strain weighing between 150-250 grams were used throughout the present study. Rats were housed at room temperature with normal day/night cycles. They 
were fed with standard diet of commercial rat chow and tap water and left to acclimatize to the environment for two weeks prior to their inclusion in the experiment. The principles of laboratory animal care were followed according to the NIH Guidelines for the Care and Use of Laboratory Animals (8), and the experimental procedures used in this study were approved by the Animal Care and Use Committee of Faculty of Medicine, Minia University, Egypt.

\section{Experimental protocol}

The rats were randomly divided into groups (10 rats each) as follows:

1) Control group: The rats received a single intraperitoneal injection (ip) of vehicle (olive oil or dimethyl sulfoxide (DMSO).

2) Acetaminophen-treated group (APAP group): Each rat of this group received paracetamol (APAP) dissolved in saline at a dose level of $2 \mathrm{gm} / \mathrm{kg}$ body weight given as a single dose orally by oral gavage (9).

3) Acetaminophen + vitamin E (APAP+ vitamin E) group: Each rat of this group received pretreatment with vitamin $\mathrm{E}$ diluted in olive oil at a dose of $100 \mathrm{mg} / \mathrm{kg}$ body weight received as a single ip dose 24 hours before receiving APAP (10).

4) Acetaminophen + sodium hydrosulfide (NaHS; H2S donor) $(\mathrm{APAP}+\mathrm{H} 2 \mathrm{~S})$ group: Each rat of this group received pretreatment with NaHS dissolved in saline at a dose level of 56 $\mu \mathrm{mol} / \mathrm{kg}$ for 2 consecutive days by ip injection before receiving APAP (11).

5) Acetaminophen + necrostatin-1 (APAP+necrostatin-1) group: Each rat of this group received pretreatment with necrostatin-1 dissolved in $2 \%$ DMSO in a phosphate buffered saline at a dose level of $1.8 \mathrm{mg} / \mathrm{kg}$ taken as a single ip injection 1 hour before receiving APAP (12).

\section{Specimen collection}

At the end of the experimental period and after overnight fasting, the rats were anaesthetized by light ether anesthesia. Blood samples were withdrawn from the abdominal aorta, collected into clean autoclaved tubes, left to clot at room temperature and then centrifuged at $3000 \mathrm{rpm}$ for $15 \mathrm{~min}$ in a cooling centrifuge. The supernatant serum was then withdrawn into labeled Eppendorf tubes and stored at $-20{ }^{\circ} \mathrm{C}$ until assayed for different parameters. After that, the liver of each rat from each group were excised, flushed with ice-cold saline, cleaned from blood and a piece from each liver was stored in $10 \%$ formalin to be used for histopathological and immuno-histochemical examination.

\section{Chemical assays}

The collected sera were used for estimation of levels of alanine transaminase (ALT), aspartate transaminase (AST), total cholesterol (TC), triglycerides (TG), HDL cholesterol (Biostc Co., EGYPT) and serum reduced glutathione (GSH) (Elabscience Biotechnology Co., Ltd., USA) by using direct colorimetric method. Serum LDL cholesterol level was determined using an equation as follows: LDL cholesterol conc. $(\mathrm{mg} / \mathrm{dl})=$ total cholesterol (Triglycerides/5) - HDL cholesterol.

The determination of serum interleukin-33 (IL-33) and serum tumor necrosis factor- $\alpha$ (TNF- $\alpha$ ) was done by enzyme-linked immunosorbent assay (ELISA) by following the manufacturer protocol (Bioassay Technology laboratory).

\section{Histological procedures}

Parts of rats' livers which were fixed in $10 \%$ neutral buffered formalin solutions were processed for preparation of paraffin blocks. Six-micrometer sections were cut, mounted on glass slides, deparaffinized with xylene, rehydrated and used for hematoxylin and eosin (H\&E) staining using standard techniques (13).

Other sections were immune-stained for caspase- 3 according to the manufacture's guidelines.

The sections were examined, and images were digitally captured using a high-resolution color digital camera (Olympus, Tokyo, Japan) mounted on the microscope (Olympus, Tokyo, Japan), connected to a computer.

Image J 22 software (open source Java image processing program) was used for area fraction measurement of the activated caspase-3 immune-positivity. The area fraction was measured in a standard measuring frame per 5 photomicrographs in each group using a magnification X 1,000 light microscope transferred to the monitored screen. Areas containing positively immunostained tissues were used for evaluation regardless of the intensity of staining (14)

\section{Statistical analysis of results}

Statistical analysis for numerical data was done by SPSS (IBM corp., Version 20). The mean (M) and standard error (SE) were determined for parameters in each group. The significance of differences observed in these groups was assessed by Kruskal-

Tab. 1. Liver transaminases, IL- 33, TNF- $\alpha$ and GSH levels in different groups.

\begin{tabular}{lccccc}
\hline Groups $(n=10)$ & \multicolumn{5}{c}{} \\
\hline Parameters & Control & APAP & APAP + Vitamin E & APAP + H $2_{2} \mathrm{~S}$ & APAP + necrostatin-1 \\
\hline Serum ALT $(\mathrm{U} / \mathrm{L})$ & $17.55 \pm 0.95$ & $43.13 \pm 2.48^{\mathrm{a}}$ & $25.08 \pm 4.89^{\mathrm{a}, \mathrm{b}}$ & $20.44 \pm 3.1^{\mathrm{b}}$ & $35.52 \pm 4.79^{\mathrm{a}, \mathrm{b}, \mathrm{c}, \mathrm{d}}$ \\
Serum AST $(\mathrm{U} / \mathrm{L})$ & $93.04 \pm 9.99$ & $166.3 \pm 12.27^{\mathrm{a}}$ & $108.44 \pm 9.2^{\mathrm{a}, \mathrm{b}}$ & $99.36 \pm 8.44^{\mathrm{b}}$ & $135.43 \pm 13.23^{\mathrm{a}, \mathrm{b}, \mathrm{c}, \mathrm{d}}$ \\
Serum TNF- $\alpha(\mathrm{ng} / \mathrm{L})$ & $17.08 \pm 3.83$ & $43.64 \pm 4.66^{\mathrm{a}}$ & $25.29 \pm 4.51^{\mathrm{a}, \mathrm{b}}$ & $20.24 \pm 3.13^{\mathrm{b}}$ & $34.59 \pm 3.13^{\mathrm{a}, \mathrm{b}, \mathrm{c}, \mathrm{d}}$ \\
Serum IL-33 $(\mathrm{ng} / \mathrm{L})$ & $40.95 \pm 5.15$ & $97.55 \pm 14.82^{\mathrm{a}}$ & $51.69 \pm 6.8^{\mathrm{a}, \mathrm{b}}$ & $45.54 \pm 6.94^{\mathrm{b}}$ & $79.19 \pm 8.83^{\mathrm{a}, \mathrm{b}, \mathrm{c}, \mathrm{d}}$ \\
Serum GSH $(\mu \mathrm{mol} / \mathrm{L})$ & $72.97 \pm 3.7$ & $33.94 \pm 2.02^{\mathrm{a}}$ & $55.07 \pm 4.96^{\mathrm{a}, \mathrm{b}, \mathrm{c}}$ & $64.45 \pm 3.15^{\mathrm{a}, \mathrm{b}}$ & $49.94 \pm 4.15^{\mathrm{a}, \mathrm{b}, \mathrm{c}}$ \\
\hline
\end{tabular}

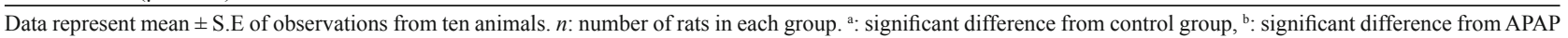
group, ${ }^{c}$ : significant difference from (APAP $+\mathrm{H}_{2} \mathrm{~S}$ ) group, ${ }^{\mathrm{d}}$ : significant difference from (APAP + vitamin E) group. Significance: $\mathrm{p}<0.05$. ALT: alanine transaminase, AST: aspartate transaminase, APAP: acetaminophen. $\mathrm{H}_{2} \mathrm{~S}$ : hydrogen sulfide, TNF- $\alpha$ : tumor necrosis factor alpha, IL-33: interleukin-33. GSH: reduced glutathione 
Tab. 2. Effects of different lines of treatment on serum lipid profile.

\begin{tabular}{|c|c|c|c|c|c|}
\hline \multicolumn{6}{|l|}{ Groups $(n=10)$} \\
\hline Parameters & Control & APAP Treated & APAP + Vitamin E & $\mathrm{APAP}+\mathrm{H}_{2} \mathrm{~S}$ & APAP + necrostatin-1 \\
\hline Total cholesterol (mg/dl) & $126.22 \pm 11.49$ & $186.13 \pm 9.39^{\mathrm{a}}$ & $138.55 \pm 13.56^{b}$ & $132.23 \pm 8.03^{\mathrm{b}}$ & $154.54 \pm 11.5^{\mathrm{a}, \mathrm{b}, \mathrm{c}, \mathrm{d}}$ \\
\hline Serum triglycerides (mg/dl) & $61.89 \pm 5.1$ & $136.88 \pm 9.19^{\mathrm{a}}$ & $71.88 \pm 7.9^{b}$ & $79.36 \pm 7.03^{\mathrm{b}}$ & $106.32 \pm 4.49^{\mathrm{a}, \mathrm{b}, \mathrm{c}, \mathrm{d}}$ \\
\hline Serum HDL cholesterol (mg/dl) & $45.63 \pm 4.3$ & $30.79 \pm 2.74^{\mathrm{a}}$ & $49.59 \pm 3.43^{\mathrm{b}}$ & $45.85 \pm 4.07^{\mathrm{b}}$ & $37.4 \pm 1.95^{\mathrm{a}, \mathrm{b}, \mathrm{c}, \mathrm{d}}$ \\
\hline Serum LDL cholesterol (mg/dl) & $68.23 \pm 4.2$ & $127.96 \pm 10.11^{\mathrm{a}}$ & $71.34 \pm 9.5^{\mathrm{b}}$ & $68.5 \pm 5.09^{\mathrm{b}}$ & $90.88 \pm 7.27^{\mathrm{a}, \mathrm{b}, \mathrm{c}, \mathrm{d}}$ \\
\hline
\end{tabular}

Data represent mean \pm S.E of observations from ten animals. $n$ : number of rats in each group. ${ }^{\text {a }: ~ s i g n i f i c a n t ~ d i f f e r e n c e ~ f r o m ~ t h e ~ c o n t r o l ~ g r o u p, ~}{ }^{\text {b }}$ significant difference from APAP group, ${ }^{c}$ : significant difference from (APAP $+\mathrm{H}_{2} \mathrm{~S}$ ) group, ${ }^{\mathrm{d}}$ : significant difference from (APAP + vitamin E) group. Significance: $\mathrm{p}<0.05$. HDL: high density lipoprotein, LDL: low density lipoprotein, APAP: acetaminophen, $\mathrm{H}_{2} \mathrm{~S}$ : hydrogen sulfide.

Wallis test and post hoc test. The significance was determined as a probability factor ( $\mathrm{p}$-value $)<0.05$.

\section{Results}

Changes in liver injury markers; alanine transaminase (ALT) and aspartate transaminase (AST) in different groups

The data presented in Table 1 show that serum alanine transaminase (ALT) and aspartate transaminase (AST) were significantly increased in the APAP-treated group as compared to the control group. The administration of vitamin $\mathrm{E}, \mathrm{H}_{2} \mathrm{~S}$, and necrostatin-1 significantly decreased the liver enzymes as compared to the APAP group. However, vitamin $\mathrm{E}$ and $\mathrm{H}_{2} \mathrm{~S}$ were more effective than Necrostatin-1 in reducing the elevated liver enzymes.

Changes in serum IL-33, TNF- $\alpha$ and GSH level in different groups

The inflammatory markers, tumor necrosis factor alpha (TNF- $\alpha$ ) and interleukin-33 (IL-33) were significantly increased in the APAP-treated group as compared to the control group. The pretreatment with vitamin $\mathrm{E}, \mathrm{H}_{2} \mathrm{~S}$, or necrostatin-1significantly reduced these inflammatory markers. The strongest anti-inflammatory effect, almost reaching the control level, was obtained by $\mathrm{H}_{2} \mathrm{~S}$ administration, while necrostatin-1 produced the weakest effect. The serum reduced glutathione (GSH) was significantly decreased in the APAP-treated group when compared to the control group. The administration of vitamin $\mathrm{E}, \mathrm{H}_{2} \mathrm{~S}$ or necrostatin-1 significantly increased the serum GSH level, albeit its level in these groups was still significantly lower than that in the control group. As shown in Table $1 . \mathrm{H}_{2} \mathrm{~S}$ produced the best effect as to the increase in GSH level, while the administrations of vitamin E or necrostatin-1 have almost similar effects.

\section{Changes in serum lipid profile in different groups}

The data presented in Table 2 show that serum total cholesterol level (TC), triglycerides (TG) and low-density lipoprotein (LDL) were significantly increased, while serum high density lipoprotein (HDL) level was decreased in APAP-treated group when compared to the control group. The administration of either vitamin E, $\mathrm{H}_{2} \mathrm{~S}$, or necrostatin-1 reduced this deterioration in lipid profile as indicated by the significantly lower TC, TG and LDL levels and significantly higher HDL level. Necrostatin-1 administration produced the weakest effect, while the effects of vitamin $\mathrm{E}$ and $\mathrm{H}_{2} \mathrm{~S}$ were almost equal.

\section{Histopathological and immuno-histochemical results}

Hematoxylin and eosin-stained section:

- Liver sections of the control group showed normal lobular architecture (Fig. 1a). Hepatocytes radiated from the central vein in cords, forming anastomosing fenestrated plates separated by the hepatic sinusoids. The portal tracts contained branches of hepatic artery, portal vein and bile duct. The hepatocytes were polyhedral with acidophilic finely granular cytoplasm and large central vesicular nuclei with prominent nucleoli.

- The examination of sections in the APAP group (Fig. 1b) showed a disrupted lobular architecture with massive interstitial hemorrhage. Marked hepatic injury especially around the central vein was observed in form of sinusoidal dilatation and massive congestion with mononuclear inflammatory cellular infiltration. Numerous degenerated hepatocytes appeared either apoptotic with deeply acidophilic cytoplasm and dark small nuclei or with foamy vacuolated cytoplasm and deformed nuclei. Interestingly, some areas exhibited a marked recruitment of inflammatory cells in the vicinity of the portal tract with prominent vascular congestion.

- (APAP + vitamin E) group showed marked morphological restoration in form of a preserved general lobular architecture with lacking evidence of major morphological injury as compared to the APAP group. Most hepatocytes had a more or less normal appearance and were arranged in cords while their nuclei had normal vesicular appearance with scarcely seen degenerated cells. Some vascular congestion, slightly dilated blood sinusoids and few small foci of mononuclear inflammatory cells infiltration were observed (Fig. 1c).

- The APAP $+\mathrm{H}_{2} \mathrm{~S}$ group showed no obvious differences as compared to the APAP + vitamin E group where restoration of normal lobular architecture with few foci of degenerated cells were observed. (Fig. 1d).

- The APAP+Necrostatin-1 group showed also a restoration of lobular architecture, but with more intensive vascular congestion and numerous degenerated foci which were fatty degenerations as compared to the APAP + vitamin $\mathrm{E}$ and APAP $+\mathrm{H}_{2} \mathrm{~S}$ groups (Fig. 1e).

Effects of different treatments on the immuno-expression of activated caspase-3

Liver sections of control group displayed normal lobular architecture with no detectable immunolabelling for activated caspase-3. APAP-treated group showed an obviously high immunolabelling for activated caspase-3. Pre-treatment of rats with vitamin 

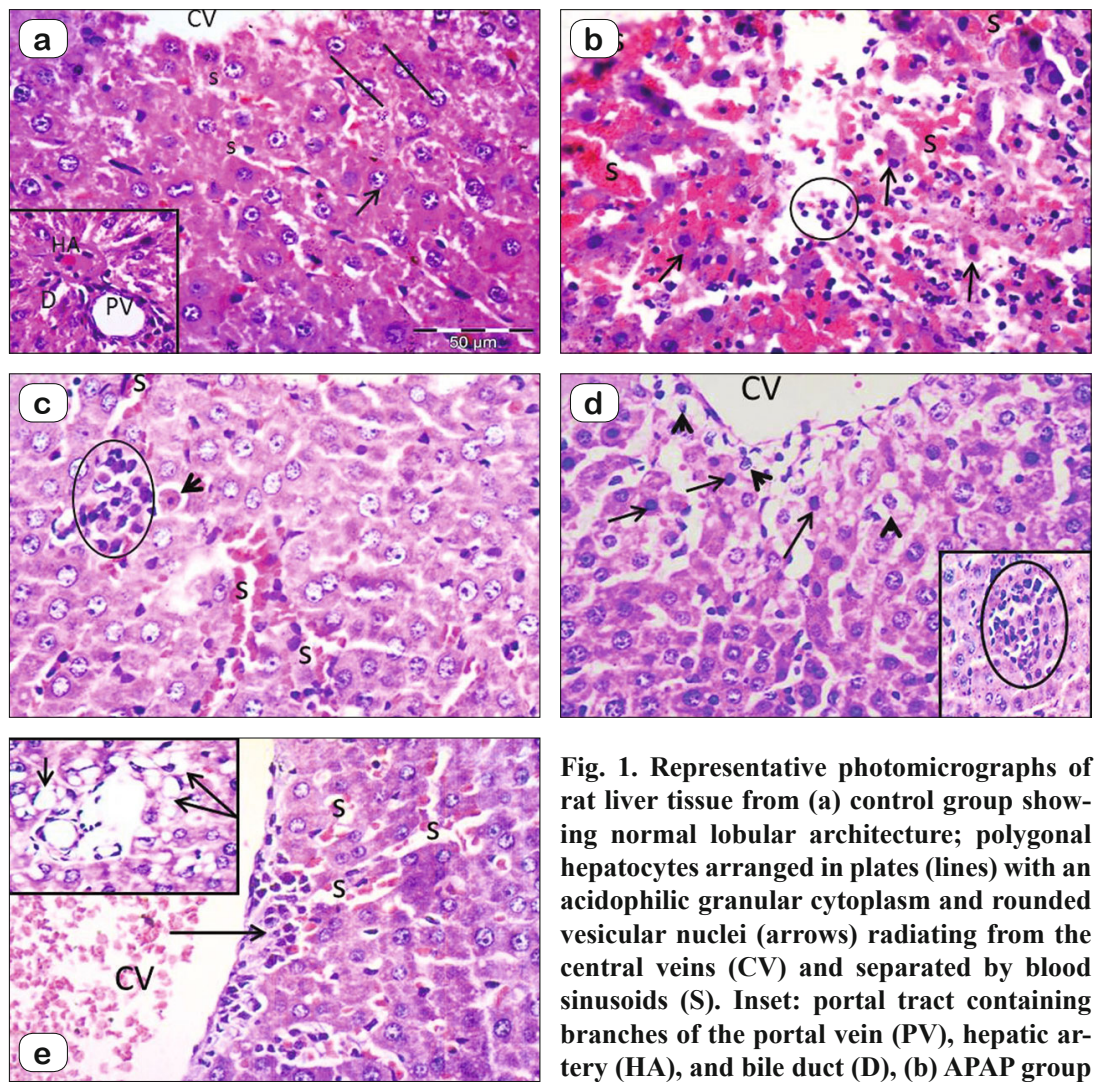

Fig. 1. Representative photomicrographs of rat liver tissue from (a) control group showing normal lobular architecture; polygonal hepatocytes arranged in plates (lines) with an acidophilic granular cytoplasm and rounded vesicular nuclei (arrows) radiating from the central veins $(\mathrm{CV})$ and separated by blood sinusoids (S). Inset: portal tract containing branches of the portal vein (PV), hepatic artery (HA), and bile duct (D), (b) APAP group showing disturbed lobular architecture with massive sinusoidal dilatation and congestion (S), mononuclear inflammatory cells infiltration (circle) and degenerated apoptotic hepatocytes (arrows). N.B.: degenerated hepatocytes with foamy vacuolated cytoplasm and deformed nuclei (arrows, inset), (c) APAP + vitamin E group showing restored normal lobular architecture with minimal congestion of slightly dilated blood sinusoids (S), small foci of mononuclear inflammatory cells infiltration (circle) and few apoptotic hepatocyte (arrowhead), (d) APAP + H2S group showing restored normal lobular architecture, few foci of degenerated cells (inset, circle), some degenerated hepatocytes surrounding central vein (CV): either small with deep acidophilic cytoplasm and dark small nuclei (arrows) or with vacuolated cytoplasm (arrow heads), (e) APAP+necrostatin-1 showing restored normal lobular architecture with central vein $(\mathrm{CV})$ congestion, slightly dilated blood sinusoids (S), small foci of mononuclear inflammatory cells infiltration (arrow) and scattered foci of fatty degenerations (inset, arrows); $\mathrm{H} \& \mathrm{E} \times 400$

E and necrostatin-1 showed few scattered immunolabeled cells. In the APAP $+\mathrm{H}_{2} \mathrm{~S}$ group, the caspase- 3 immunolabeled cells were completely abolished. The immunolabeling was mainly confined to hepatocytes and some endothelial cells. The expression was mostly cytoplasmic (Fig. 2).

Scoring for active caspase- 3 of different experimental groups The apoptotic marker, caspase-3, was significantly increased in the APAP-treated group $(8.33 \pm 1.63)$ as compared to the control group $(0.67 \pm 0.08)$. The treatment with either vitamin $\mathrm{E}, \mathrm{H}_{2} \mathrm{~S}$, or necrostatin-1 significantly reduced the apoptotic marker. The best improvement was produced by $\mathrm{H}_{2} \mathrm{~S}$ administration. Its effect was the closest to the result seen at the control level $(0.5 \pm 0.05)$, while the administration of vitamin $\mathrm{E}$ and necrostatin-1 produced almost similar effects: $(1.33 \pm 0.25$ and $1.83 \pm 0.37$, respectively (Fig. 2 f).

\section{Discussion}

Acetaminophen (APAP) is the most widely used antipyretic and analgesic drug. It is considered to be safe at the recommended therapeutic concentrations. However, an overdose of APAP can cause severe liver damage resulting in ALI and acute liver failure (ALF). Among the different animal models, the model of APAP-induced liver injury is widely used because it is available and cheap, while inducing hepatotoxicity with the same metabolic features as in humans (7). This model is even more important now with a potentially significant increase in the use of APAP owing to the COVID-19 pandemic (2). That is why it was selected in the current study.

In the present study there was a significant increase in the serum level of ALT and AST along with disturbed hepatic architecture as seen in the histological images, thus indicating liver injury induced by APAP in the APAP-treated group as compared to the control one. Elevated serum levels of ALT and AST are indicative of the loss of functional integrity of hepatic cell membranes, and consequential release of the latter enzymes into the circulation after hepatocellular damage. These results come in line with previous studies $(15,16)$, and (17).

The serum GSH level was significantly decreased in the APAP-treated group as compared to the control group. GSH is one of the most common biologic non-enzymatic antioxidants. Its function includes the removal of free radicals such as $\mathrm{H}_{2} \mathrm{O}_{2}$ and superoxide anions, maintenance of membrane protein thiols and action as a substrate for glutathione peroxidase and glutathione reductase. Thus, a significant decrease in GSH level promoted by APAP leads to a reduction in the effectiveness of the antioxidant enzyme defense system, thereby sensitizing the cells to ROS(4). In addition, GSH serves as a sensitive marker of oxidative stress and plays an important role in maintaining the integrity of the cell (18). Another study reported that GSH forms the first line of defense against oxidative stress by direct interaction of its thiol group with ROS and/or it can be involved in the enzymatic detoxification reaction of ROS as a cofactor or as a coenzyme (19).

The above data implicate that the APAP-induced injurious effect on the liver can be partly carried out during the period of an increasing oxidative stress by decreasing $\operatorname{GSH}(19,20)$ and $(18$, 21 ). Oxidative stress is one of the major pathways to initiate lipid peroxidation that consumes HDL which is a free radical scavenger. This explains the low HDL level seen in this study (22) 

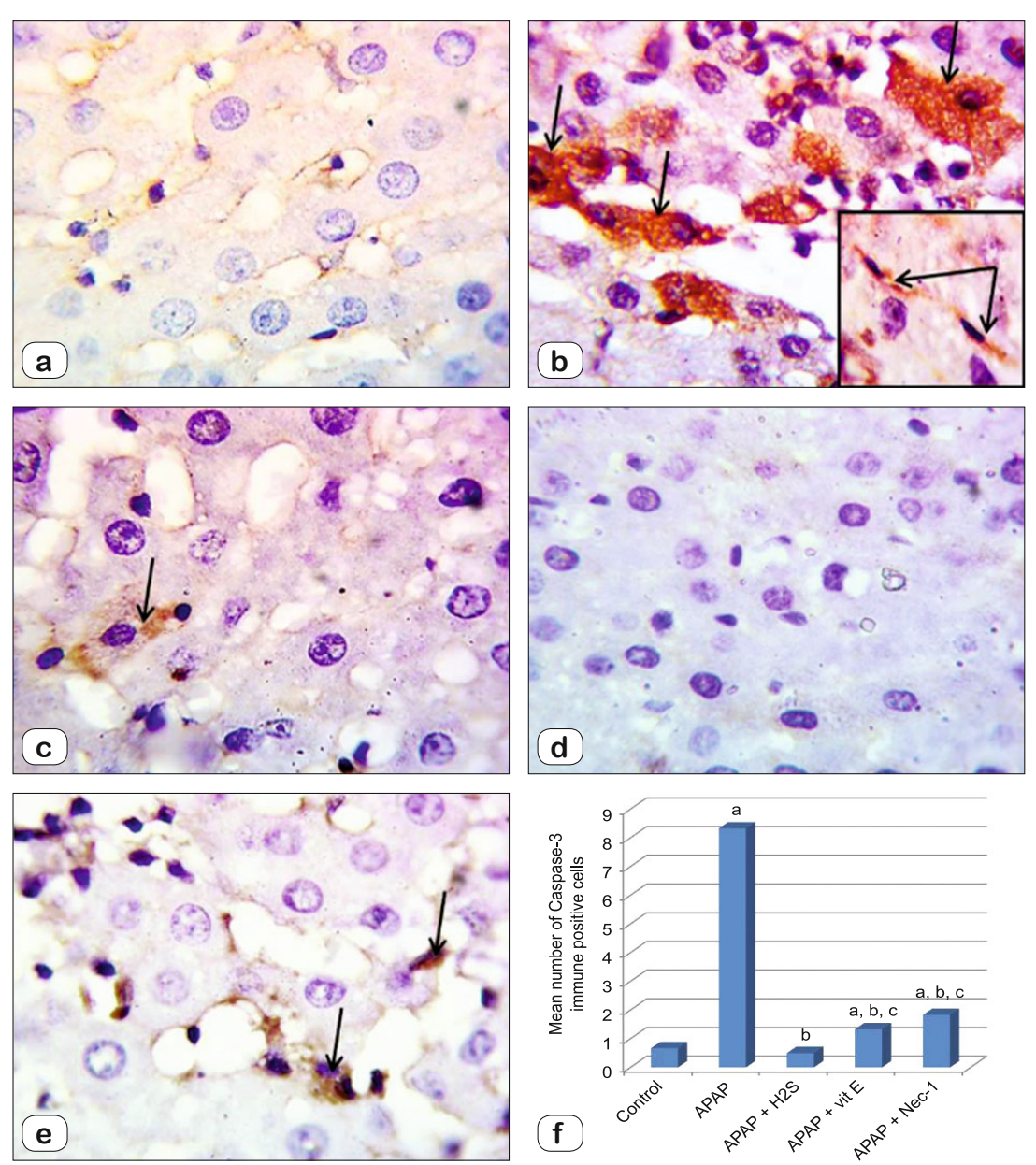

Fig. 2. Photomicrographs from liver sections immune-stained for activated caspase-3: (a) Control group showing no immune reaction, (b) APAP group showing positive fine brown cytoplasmic granules in some hepatocytes (arrows) and some endothelial cells (arrows in inset), (c) APAP+ vitamin E group showing a decreased positive reaction in few hepatocytes (arrow), (d) APAP+ $\mathrm{H}_{2} \mathrm{~S}$ group showing no immune reaction, (e) APAP+necrostatin-1 group showing a decreased positive reaction in few cells (arrow), (f) the mean number of caspase-3 immune positive cells in the studied groups $(n=10)$. a: significant difference from the control group, b: significant difference from the APAP group, c: significant difference from (APAP+H2S) group, d: significant difference from (APAP + vitamin $E)$ group. Significance: $p<0.05$. APAP: acetaminophen. $\mathrm{H}_{2} \mathrm{~S}$ : hydrogen sulfide. Immunohistochemistry, counter stained with H, X1000.

The administration of vitamin $\mathrm{E}, \mathrm{H}_{2} \mathrm{~S}$ or NEC-1 before receiving APAP significantly decreased the serum level of ALT and AST and elevated the serum GSH level as compared to the APAP-treated group, thus indicating the protective effects of these agents on APAPinduced liver injury. These results come in line with some previous studies $(23,24,25)$. These studies demonstrated that the treatment with vitamin $\mathrm{E}, \mathrm{H}_{2} \mathrm{~S}$ and NEC-1, respectively was accompanied with improvement in serum aminotransferase levels and GSH, and that the return of ALT values to the normal range is usually associated with histological improvement in disease activity (steatosis, inflammation, cell injury), healing of parenchyma and regeneration of hepatocytes (26), which is attributed to the anti-oxidative activity by reducing the production of lipid peroxides, and which thereby explains the correction of dyslipidemia, as seen in this study.
The main role of vitamin $\mathrm{E}$ as an antioxidant is well understood to be that of a scavenger of free radicals, thereby preventing the depletion of GSH (27). $\mathrm{H}_{2} \mathrm{~S}$ does not produce the antioxidant effect through a single mechanism. Multiple targets and signaling pathways are involved. $\mathrm{H}_{2} \mathrm{~S}$ can stimulate cellular enzymatic or non-enzymatic antioxidants to scavenge free radicals. This may be secondary to the direct effect on antioxidants or an indirect action through activation of various signaling proteins (28).

Nec-1 has no direct antioxidant activity as compared to vitamin $\mathrm{E}$ which is an antioxidant by itself. Nec-1 does not act as a scavenger. It inhibits receptor-interacting protein kinase 1 (RIPK1) which is the key mediator of cells' death, inflammation, and necrosome formation and on that account, it decreases intracellular ROS production; Nec1 prevents glutamate-induced toxicity in liver. Glutamate inhibits cysteine transport and depletes intracellular GSH levels (29).

TNF- $\alpha$ and IL-33 are inflammatory mediators that are believed to promote liver injury during inflammation. These data match our finding regarding the significant increase in these inflammatory cytokines in the APAP-treated group as compared to the control group, which can prove the inflammatory cascade to be one of the pathophysiological mechanisms of APAP-induced liver injury.

It is believed that sustained elevated levels of TNF- $\alpha$ promote apoptosis, necrosis and necroptosis in hepatocytes and, consequently the liver damage. TNF- $\alpha$ induced apoptosis and necroptosis of hepatocytes are believed to mediate, at least in part, liver damage during inflammation in liver toxicity caused by APAP (30).

In keeping with these data, the present study showed a significant increase in the hepatic immune-expression of caspase-3, a lysosomal enzyme involved in the apoptotic pathway, thus indicating an induction of apoptosis by APAP treatment. This result has been obtained in previous studies such as $(31,32,33)$. These studies reported that high doses of APAP led to apoptosis and significantly increased caspase-3 levels.

The administration of vitamin $\mathrm{E}, \mathrm{H}_{2} \mathrm{~S}$ and NEC-1 prior to that of APAP in rats significantly decreased these proinflammatory markers and decreased the immune-expression of caspase- 3 denoting their anti- inflammatory and anti-apoptotic effects.

The anti-apoptotic and anti-inflammatory effects of both vitamin $\mathrm{E}$ and $\mathrm{H}_{2} \mathrm{~S}$ are well documented in several studies such as $(34,35,36)$. 
The anti-inflammatory effect of Nec-1 reported in our study is in line with other studies such as (37), and (38) which reported a strong relationships between necroptosis and release of cytokines, anti-inflammatory effect of $\mathrm{Nec}-1$ and its inhibitory effect on TNF- $\alpha$ induced necroptosis (39). Moreover, it was suggested that necroptosis enhances TNF- $\alpha$ induced gene transcription. The greatly elevated cytokine expression appears to be a common feature of necroptosis as it was found in a panel of necroptotic cell lines and can be activated by different types of necroptotic stimuli including TNF- $\alpha$ (40).

Nec-1 blocks TNF- $\alpha$ induced necroptosis by inhibition of RIPK1 activity that mediates activation of NF- $\mathrm{BB}$ and mitogenactivated protein kinase (MAPK), apoptosis and necroptosis, and thus decreases TNF- $\alpha$ level (41).

Some studies have demonstrated the direct role of necroptosis in IL-33 release. (42). Nec-1 downregulates liver IL-33 protein expression and attenuates hepatocellular damage and serum IL-33 (43).

In the present study, we found a significant decrease in the hepatic immune-expression of caspase-3 in the (Nec-1)-treated group as compared to the APAP-treated group. This result comes in line with studies such as $(44,45)$ which reported that the caspase activation is slower and lower in the presence of Nec-1, thus demonstrating that the necroptosis blockage can also delay the apoptotic pathway and suggesting that apoptosis and necroptosis share some molecular mechanisms during the first phase of the two processes.

\section{Conclusions}

We concluded that APAP has hazardous effects on hepatocytes when administered in high doses, while the cellular damage occurs via different underlying mechanisms. Nevertheless, this effect can be counteracted by certain hepatoprotective agents such as $\mathrm{H}_{2} \mathrm{~S}$, vitamin E and NEC-1 by their anti-inflammatory, anti-oxidant and anti-apoptotic actions. Albeit. clinical studies will be needed to proof the use of these agents as an adjuvant therapy when APAP is needed to be used for a long period or in critical patients such as in those with COVID-19.

\section{References}

1. Rodríguez-Morales AJ, Cardona-Ospina JA, Murillo-Muñoz MM. Gastroenterologists, hepatologists, COVID-19 and the use of acetaminophen. Clin Gastroenterol Hepatol 2020; 18 (9): 2142-2143.

2. Bhadelia N. Coronavirus: hospitals must learn from past pandemics. Nature 2020; 578 (7794): 193.

3. Hinson JA, Pohl LR, Monks TJ, Gillette JR. Acetaminophen-induced hepatotoxicity. Life Sci 1981; 29 (2): 107-116.

4. Tas N, Altinbas A, Noyan T, Kokturk S, Ayhan S, Canakci E. Acute acetaminophene-induced hepatotoxicity and nephrotoxicity; therapeutic effect of dexmedetomidine. Bratisl Med J 2019; 120 (4): 270-276.

5. Yoon E, Babar A, Choudhary M, Kutner M, Pyrsopoulos N. Acetaminophen-Induced Hepatotoxicity: a Comprehensive Update. J Clin Transl Hepatol 2016; 4 (2): 131-142.
6. Jaeschke H, McGill MR, Williams CD, Ramachandran A. Current issues with acetaminophen hepatotoxicity - a clinically relevant model to test the efficacy of natural products. Life Sci 2011; 88 (17-18): $737-745$.

7. Mazaleuskaya LL, Sangkuhl K, Thorn CF, FitzGerald GA, Altman RB, Klein TE. PharmGKB summary: pathways of acetaminophen metabolism at the therapeutic versus toxic doses. Pharmacogenet Genom 2015; 25 (8): 416.

8. Council NR. Guide for the care and use of laboratory animals 2010.

9. McGill MR, Williams CD, Xie Y, Ramachandran A, Jaeschke H. Acetaminophen-induced liver injury in rats and mice: comparison of protein adducts, mitochondrial dysfunction, and oxidative stress in the mechanism of toxicity. Toxicol Appl Pharmacol 2012; 264 (3): 387-394.

10. Karakilcik AZ, Hayat A, Zerin M, Cay M. Effects of intraperitoneally injected selenium and vitamin $\mathrm{E}$ in rats anesthetized with halothane. J Trace Elements Med Biol 2003; 17 (1): 33-38.

11. Yuan Y, Zheng J, Zhao T, Tang X, Hu N. Hydrogen sulfide alleviates uranium-induced acute hepatotoxicity in rats: Role of antioxidant and antiapoptotic signaling. Environ Toxicol 2017; 32 (2): 581-593.

12. Kim SJ, Lee SM. Necrostatin-1 Protects Against D-Galactosamine and Lipopolysaccharide-Induced Hepatic Injury by Preventing TLR4 and RAGE Signaling. Inflammation 2017.

13. Bancroft JD, Gamble M. Theory and practice of histological techniques: Elsevier Health Sciences; 2008.

14. Mohammed N, Ali A, Gamal El-Tahawy N, Rifaai R. Effect of Hydroxyprogesterone (17-OHPC) on Placenta in a Rat Model of Preeclampsia: Histological and Immunohistochemical Study. J Cytol Histol 2018; 9: 496.

15. Ilavenil S, Al-Dhabi NA, Srigopalram S, Ock Kim Y, Agastian P, Baru R, et al. Acetaminophen Induced Hepatotoxicity in Wistar Rats - A Proteomic Approach. Molecules 2016; 21 (2): 161.

16. Bozogluer E, Madenoglu H, Aksu R, Bicer C, Yazici C, Boyaci A. The effect of different doses of flumazenil on acetaminophen toxicity in rats. Bratisl Med J 2012; 113 (9): 525-528.

17. Alanazi A, Algfeley SG, Al-Hosaini KA, Korashy HM, Imam F, Nagi MN. Therapeutic potential of carfilzomib, an irreversible proteasome inhibitor, against acetaminophen-induced hepatotoxicity in mice. J Biochem Mol Toxicol 2017; 31 (4).

18. Chowdhury A, Jahan N, Temitope IA, Wang S. Current etiological comprehension and therapeutic targets of acetaminophen-induced hepatotoxicity. Pharmacol Resh 2020: 105102.

19. Yang J, Wang XY, Xue J, Gu ZL, Xie ML. Protective effect of apigenin on mouse acute liver injury induced by acetaminophen is associated with increment of hepatic glutathione reductase activity. Food Function 2013; 4 (6): 939-943.

20. Pires DA, Marques PE, Pereira RV, David BA, Gomides LF, Dias AC, et al. Interleukin-4 deficiency protects mice from acetaminopheninduced liver injury and inflammation by prevention of glutathione depletion. Inflamm Res 2014; 63 (1): 61-69.

21. More SS, Nugent J, Vartak AP, Nye SM, Vince R. Hepatoprotective Effect of psi-Glutathione in a Murine Model of Acetaminophen-Induced Liver Toxicity. Chem Res Toxicol 2017; 30 (3): 777-784.

22. Egbung GE, Atangwho IJ, Odey OD, Ndiodimma VN. The lipid lowering and cardioprotective effects of Vernonia calvoana ethanol extract in acetaminophen-treated rats. Medicines 2017; 4 (4): 90. 
$732-738$

23. El Hadi H, Vettor R, Rossato M. Vitamin E as a Treatment for Nonalcoholic Fatty Liver Disease: Reality or Myth? Antioxidants (Basel, Switzerland) 2018; 7 (1): 12.

24. Cen XH, Zhang ZX, Wang T, Wang YS, Ji YL, Yan J, et al. The Role of Hydrogen Sulfide in Acute Liver Injury Induced by Traumatic Stress in Rats. Fa Yi Xue Za Zhi 2016; 32 (2): 81-85.

25. Takemoto K, Hatano E, Iwaisako K, Takeiri M, Noma N, Ohmae S, et al. Necrostatin-1 protects against reactive oxygen species (ROS)-induced hepatotoxicity in acetaminophen-induced acute liver failure. FEBS open bio 2014; 4: 777-787.

26. R. Parmar S, Patel H, K K. Hepatoprotective activity of some plants extract against paracetamol induced hepatotoxicity in Wistar rats 2010 . 101-106 p.

27. Şener G, Şehirli AÖ, Ayanoğlu-Dülger G. Protective effects of melatonin, vitamin $\mathrm{E}$ and $\mathrm{N}$-acetylcysteine against acetaminophen toxicity in mice: a comparative study. J Pineal Res 2003; 35 (1): 61-68.

28. Xie ZZ, Liu Y, Bian JS. Hydrogen Sulfide and Cellular Redox Homeostasis. Oxid Med Cell Longev 2016; 2016: 6043038.

29. Xu X, Chua CC, Kong J, Kostrzewa RM, Kumaraguru U, Hamdy RC, et al. Necrostatin-1 protects against glutamate-induced glutathione depletion and caspase-independent cell death in HT-22 cells. J Neurochem 2007; 103 (5): 2004-14.

30. Han D, Hanawa N, Saberi B, Kaplowitz N. Mechanisms of liver injury. III. Role of glutathione redox status in liver injury. Amer J Physiol Gastrointest Liver Physiol 2006; 291 (1): G1-7.

31. Lorz C, Justo P, Belan Sanz ANA, Egido J, Ortiz A. Role of Bcl$\mathrm{xL}$ in paracetamol-induced tubular epithelial cell death. Kidney Internat 2005; 67 (2): 592-601.

32. Kandemir MF, Kucukler S, Eldutar E, Caglayan C, Gülçin İ. Chrysin Protects Rat Kidney from Paracetamol-Induced Oxidative Stress, Inflammation, Apoptosis, and Autophagy: A Multi-Biomarker Approach. Sci Pharmaceut 2017; 85 (1).

33. Jaeschke H, Duan L, Akakpo JY, Farhood A, Ramachandran A. The role of apoptosis in acetaminophen hepatotoxicity. Food Chem Toxicol 2018; 118: 709-718.

34. Abdulkhaleq FM, Alhussainy TM, Badr MM, Khalil AAA, Gammoh O, Ghanim BY, et al. Antioxidative stress effects of vitamins C, E, and B12, and their combination can protect the liver against acetaminopheninduced hepatotoxicity in rats. Drug Design, Develop Ther 2018; 12: 3525.
35. Castelblanco M, Lugrin J, Ehirchiou D, Nasi S, Ishii I, So A, et al. Hydrogen sulfide inhibits NLRP3 inflammasome activation and reduces cytokine production both in vitro and in a mouse model of inflammation. J Biol Chem 2018; 293 (7): 2546-2557.

36. Fouad A, Hafez H, Hamouda A. Hydrogen sulfide modulates IL-6/ STAT3 pathway and inhibits oxidative stress, inflammation, and apoptosis in rat model of methotrexate hepatotoxicity. Human Exp Toxicol 2020; 39 (1): 77-85.

37. Zhou Y, Dai W, Lin C, Wang F, He L, Shen M, et al. Protective effects of necrostatin-1 against concanavalin A-induced acute hepatic injury in mice. Mediators Inflamm 2013; 2013: 706156.

38. Sawai H. Characterization of TNF-induced caspase-independent necroptosis. Leuk Res 2014; 38 (6): 706-713.

39. Liao Y, Wang HX, Mao X, Fang H, Wang H, Li Y, et al. RIP1 is a central signaling protein in regulation of TNF-alpha/TRAIL mediated apoptosis and necroptosis during Newcastle disease virus infection. Oncotarget 2017; 8 (26): 43201-43217.

40. Zhu K, Liang W, Ma Z, Xu D, Cao S, Lu X, et al. Necroptosis promotes cell-autonomous activation of proinflammatory cytokine gene expression. Cell death \& disease 2018; 9 (5): 500.

41. Sawai H. Induction of Apoptosis in TNF-Treated L929 Cells in the Presence of Necrostatin-1. Int J Mol Sci 2016; 17 (10).

42. Shlomovitz I, Erlich Z, Speir M, Zargarian S, Baram N, Engler $\mathbf{M}$, et al. Necroptosis directly induces the release of full-length biologically active IL-33 in vitro and in an inflammatory disease model. FEBS J 2019; 286 (3): 507-522.

43. Yang J, Zhao Y, Zhang L, Fan H, Qi C, Zhang K, et al. RIPK3/ MLKL-Mediated Neuronal Necroptosis Modulates the M1/M2 Polarization of Microglia/Macrophages in the Ischemic Cortex. Cerebral cortex (New York, NY: 1991) 2018; 28 (7): 2622-2635.

44. Wang Y-Q, Wang L, Zhang M-Y, Wang T, Bao H-J, Liu W-L, et al. Necrostatin-1 Suppresses Autophagy and Apoptosis in Mice Traumatic Brain Injury Model. Neurochem Res 2012; 37 (9): 1849-1858.

45. Polito L, Bortolotti M, Pedrazzi M, Mercatelli D, Battelli MG, Bolognesi A. Apoptosis and necroptosis induced by stenodactylin in neuroblastoma cells can be completely prevented through caspase inhibition plus catalase or necrostatin-1. Phytomedicine 2016; 23 (1): 32-41.

Received March 24, 2021: Accepted April 24, 2021. 